\title{
Development and Validation of the Online Cooperative Learning Anxiety Scale
}

\author{
Hiroki Yoshida, Seiji Tani, Tomoko Uchida, Jitsuko Masui, Minori Fukushima, and Akira Nakayama
}

\begin{abstract}
Anxiety is considered to be one of the key psychological contributing factors to learners' behavior, attitude and achievements in online cooperative learning. Online cooperative learning requires learners to operate the Internetbased learning system properly, learn autonomously and cooperate with others effectively with the aim of accomplishing a specific goal. In such a learning situation, it is anticipated that some learners might feel uneasy or fearful about using a computer and the Internet, monitoring and regulating their learning process, and communicating and collaborating with new acquaintances. However, few studies have focused on social aspects of learners' anxiety in online cooperative learning. This study purposed to identify learners' anxiety in online cooperative learning situations, and to develop and validate the online cooperative learning scale (OCLAS). As a result, 13 anxiety statements were identified as items for the OCLAS which includes three sub-scales: computer anxiety, communication anxiety, and online learning anxiety.
\end{abstract}

Index Terms - Anxiety, cooperative learning, computer-mediated communication, scale development, online learning.

\section{INTRODUCTION}

Cooperative team skills have become an essential competency in the knowledge-based and global society [1], [2]. Cooperative learning can be defined as "a set of processes which help people interact in order to accomplish a specific goal or develop an end product which is usually content specific" [3]. The cooperative learning model developed by Johnson and Johnson [4], [5] incorporates five elements: 1) positive interdependence, 2) individual accountability, 3) promotive interaction, 4) social skills, and 5) group processing. When these elements are well structured into the instructional format, cooperative learning leads to increase learners' academic performance, participation, responsibility [6], basic needs, and intrinsic motivation [6], [7].

With the development and diffusion of computer-mediated communication (CMC) technology, cooperative learning is no longer limited to traditional classroom settings [8]. It is now implemented in virtual pedagogical settings. Internet-based online cooperative learning enables learners who are far away from each other collaborate and achieve a common goal. Bliss and Lawrence [9], [10] reported that team work through computer-mediated collaboration resulted in

Manuscript received August 29, 2014; revised November 29, 2014. This work was supported by JSPS KAKENHI Grant Number 25350360.

Hiroki Yoshida, Seiji Tani, Jitsuko Masui, and Minori Fukushima are with Tokoha University, Shizuoka, Japan (e-mail: h-yoshida@av-lab.org).

Uchida Tomoko is with Jeju National University, Jeju, Korea.

Akira Nakayama is with Ehime University, Matsuyama, Japan. significant increase of student participation, frequency of interaction, and the quality of students' conversation. However, few works have focused on learners' psychological aspects that affect their behavior, attitude, and achievements in online cooperative learning.

In the field of computer education and online education, previous studies have identified several personal traits that influence learners' behavior and performance. Among these traits, computer anxiety has consistently affected learners' achievements in online learning [11].

Simonson et al. [12] defined computer anxiety as "fear or apprehension felt by individuals when they used computers, or when they considered the possibility of computer utilization". Saadé and Kira [13] reported that about half of the adults including university students have some sort of computer anxiety. Computer anxiety is known as a strong determinant of perceived ease of use of a computer-related system [13]-[16] which leads to academic performance in computer-based education.

Many previous studies have purposed to identify the contents and structure of computer anxiety, Internet anxiety, and e-learning anxiety. Heissen et al. [17] developed a "Computer Anxiety Rating Scale (CARS)" which consists of 19 items that measure users' computer anxiety on a five-point Likert scale. Havelka and Beasley [18] performed a factor analysis and revealed four distinct factors in the CARS: general anxiety toward computer usage, confidence in learning ability, motivation to learn, and power or control of usage. Although CARS is a well-used valid scale, the problem of applying CARS in an Internet-based cooperative learning situation is that CARS only focuses on anxiety in operating a computer-meditated system or learning how to operate the system, and does not focus on the learning process, performance and interaction among learners.

Internet anxiety and e-learning anxiety appears similar to computer anxiety but is considered a different concept [19]. Presno [20] revealed four factors of Internet anxiety: Internet terminology anxiety, net search anxiety, Internet time delay anxiety, and general fear of Internet failure. Tsai [21] developed an "Online Learning Strategies Scale (OLSS)" consisting of 20 items which includes 3 items that measure Internet anxiety. OLSS focuses not only on fear or apprehension in operating an Internet-based system, but also on anxiety about the learning process and achievements. However, OLSS mainly targets learners who take e-learning courses that require individual, self-regulated learning, and therefore, cannot measure learners' anxiety to communicate and cooperate with others via the Internet.

Different from traditional "e-learning" or Web-based training, online cooperative learning requires learners to communicate and work together cooperatively in order to 
accomplish a common and specific goal. In such a learning situation, it is anticipated that learners might have fear or apprehension in communicating and collaborating with other learners. In fact, recent studies point out negative effects of social anxiety on computer-mediated communication, leading to decrease users' attitude toward use of the system and their learning behavior [22]-[25].

A possible solution to this problem is to identify what learners fear or feel uneasy when they learn cooperatively via the Internet, and to develop a measure of online cooperative learning anxiety. Therefore, this study aims to identify the contents and structure of learners' anxiety in online cooperative learning.

\section{PURPOSE}

The purpose of this study is to identify the contents and structure of learners' anxiety in learning cooperatively via the Internet, and as a result, develop and validate an Online Cooperative Learning Anxiety Scale (hereinafter abbreviated as OCLAS).

The research questions to be addressed in this study are: 1) What are university students uneasy, fearful or worried about when they learn cooperatively with new acquaintances via the Internet? 2) How many factors assist to explain the structure of learners' anxiety for online cooperative learning? 3) How valid and reliable is the OCLAS?

\section{PILOT STUDY}

Pilot study was conducted from October 15th to 26th, 2012, with the purpose of identifying the contents and structure of university students' anxiety in online cooperative learning, and consequently, creating a pool of candidate items of the OCLAS [26].

\section{A. Participants}

Participants were 31 Japanese first-year university students who participated in Korean language classes. Among them, 25 (80.65 percent) were females and 6 were $(19.35$ percent $)$ males. Most of the students (74.19 percent) had never communicated with a Korean before. Participants were to experience online cooperative learning with Korean university students in Jeju, Korea in a group of five students: two or three Japanese students and two or three Korean students.

\section{B. Questionnaire}

A written form of open-ended self-report questionnaire was used to identify learners' anxiety for online cooperative learning. Before the Internet-based cooperative learning session, participants were asked what they fear of feel apprehensive about when they learn cooperatively with a new acquaintance via the Internet.

\section{Anxiety in Online Cooperative Learning}

The KJ method (affinity diagramming) was used to categorize participants' responses with similar contents or characteristics together. The diagramming process was paneled by three researchers with at least ten years experience in research and teaching: an educational technology researcher, a language education researcher, and an educational psychology researcher. As a result, the following 17 statements were determined for the candidate items of anxiety in online cooperative learning (see Table I).

\begin{tabular}{|c|c|}
\hline Items & Frequency \\
\hline 1. I fear of communicating with a new acquaintance. & 20 \\
\hline 2. I fear of making mistakes I cannot correct. & 19 \\
\hline $\begin{array}{l}\text { I fear of hitting the wrong key or clicking the wrong } \\
\text { hyperlink. }\end{array}$ & 18 \\
\hline $\begin{array}{l}\text { I am tense and nervous while participating in group } \\
\text { discussions. }\end{array}$ & 18 \\
\hline 5. I am worried if I can gather needed information. & 18 \\
\hline $\begin{array}{l}\text { I am worried if I can communicate effectively with } \\
\text { other learners. }\end{array}$ & 18 \\
\hline $\begin{array}{l}\text { 7. I am worried if I can understand computer-related } \\
\text { terms. }\end{array}$ & 17 \\
\hline 8. I am worried if I can tell others what I want to say. & 17 \\
\hline $\begin{array}{l}\text { I am worried if I can accomplish the learning } \\
\text { objective. }\end{array}$ & 17 \\
\hline 10. I feel apprehensive about using computers. & 16 \\
\hline 11. I am worried if I can properly operate the system. & 15 \\
\hline $\begin{array}{l}\text { 12. I am worried about my achievements in online } \\
\text { cooperative learning. }\end{array}$ & 13 \\
\hline 13. I feel apprehensive about learning via the Internet. & 12 \\
\hline $\begin{array}{l}\text { I4. am worried if I can understand what other learners } \\
\text { are saying. }\end{array}$ & 3 \\
\hline $\begin{array}{l}\text { 15. I am worried if I can understand the instructions of } \\
\text { operating the system. }\end{array}$ & 2 \\
\hline 16. I fear of invading other learners' privacy. & 1 \\
\hline $\begin{array}{l}\text { If. I fear not knowing when it is appropriate to make } \\
\text { comments. }\end{array}$ & 1 \\
\hline
\end{tabular}

The 17 candidate items of online cooperative learning anxiety were classified using Hayashi's quantification method type III (correspondence analysis). Item \#14 (I am worried if I can understand what other learners are saying.), \#15 (I am worried if I can understand the instructions of operating the system.), \#16 (I fear of invading other learners' privacy.), and \#17 (I fear not knowing when it is appropriate to make comments.) were deleted from further analysis because few participants responded that they had these three kinds of anxiety, and if the items were included in the statistical analysis, they put too much category weight to all of the axes. Thus, a pool of 13 anxiety items was selected as the candidate items of the OCLAS.

Table II shows the normalized category weights given to participants' anxiety in online cooperative learning. According to the tendency of the decrease of the eigenvalues (first axis: 0.303 , second axis: 0.287 , third axis: 0.055) and the increase of the cumulative proportion (first axis: 35.24 percent, second axis: 68.67 percent, third axis: 75.02 percent), two axes were determined and interpreted. 
TABLE II: NORMALIZED CATEGORY WEIGHTS TO PARTICIPANTS' ANXIETY IN ONLINE COOPERATIVE LEARNING

\begin{tabular}{l|r|r}
\hline \hline \multicolumn{1}{c|}{ Category } & Axis 1 & \multicolumn{1}{c}{ Axis2 } \\
\hline \hline 11. $\begin{array}{l}\text { I am worried if I can properly operate the } \\
\text { system. }\end{array}$ & 1.305 & -0.776 \\
\hline 10. I feel apprehensive about using computers. & 1.189 & -0.677 \\
\hline 7. I am worried if I can understand & 1.044 & -0.573 \\
\hline computer-related terms. & 0.921 & -0.699 \\
\hline $\begin{array}{l}\text { I fear of hitting the wrong key or clicking the } \\
\text { wrong hyperlink. }\end{array}$ & 0.798 & -0.397 \\
\hline 2. I fear of making mistakes I cannot correct. & 0.243 & 1.272 \\
\hline 13. I feel apprehensive about learning via the \\
\hline Internet.
\end{tabular}

Among the 13 anxiety items decided as the initial OCLAS, 9 items correspond to anxiety statements described in previous studies. Item \#2 (I fear of making mistakes I cannot correct.), \#3 (I fear of hitting the wrong key or clicking the wrong hyperlink.), \#10 (I feel apprehensive about using computers.), and \#11 (I am worried if I can properly operate the system.) are same as the anxiety items that are included in the CARS [17], [18]. Item \#5 (I am worried if I can gather needed information.), \#7 (I am worried if I can understand computer- related terms.), and \#13 (I feel apprehensive about learning via the Internet.) are statements related with Internet anxiety factors noted by Presno [20]. Item \#9 (I am worried if I can accomplish the learning objective.), and \#12 (I am worried about my achievements in online cooperative learning.) are statements that are similar to the Internet anxiety items presented in the OLSS [21].

The rest of the initial OCLAS items cannot be found in other computer anxiety scales, Internet anxiety scales, and e-learning anxiety scales. However, item \#1 (I fear of communicating with a new acquaintance.), \#4 (I am tense and nervous while participating in group discussions.), and \#8 (I am worried if I can tell others what I want to say.) are statements that are suggested by McCroskey et al. [27] in the "Personal Report of Communication Apprehension (PRCA-24)" which is a scale that is widely used by researchers and educators to predict anxiety about communication with other people.

Fig. 1 shows a two-dimensional scatter graph of the category scores of each anxiety item. Results indicate that participants' anxiety in online cooperative learning with new acquaintances can be classified into three clusters.

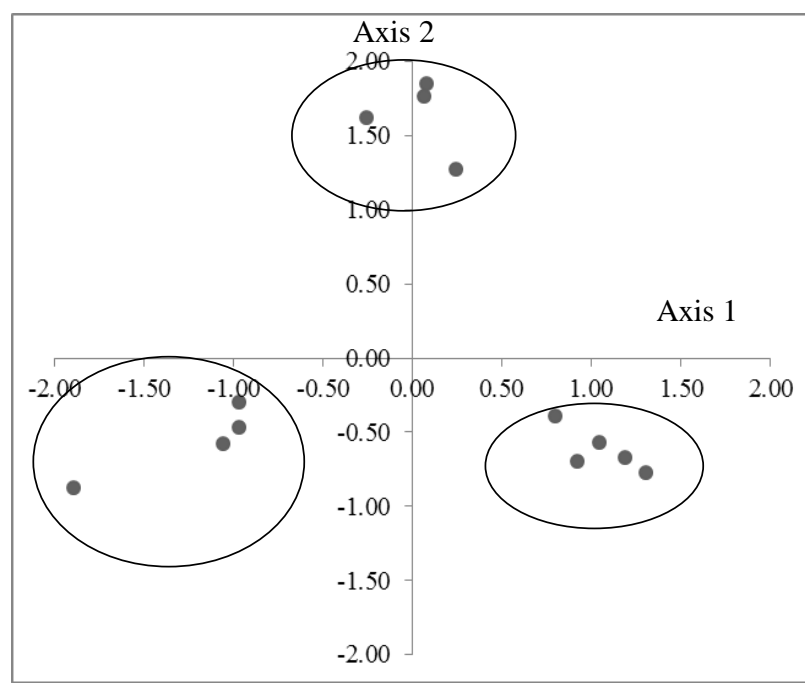

Fig. 1. Two-dimensional plot graph of participants' anxiety for online cooperative learning.

The first cluster consists of five items: \#2 (I fear of making mistakes I cannot correct.), \#3 (I fear of hitting the wrong key or clicking the wrong hyperlink.), \#7 (I am worried if I can understand computer-related terms.), \#10 (I feel apprehensive about using computers.), and \#11 (I am worried if I can properly operate the system.) that had high category scores on the first correlation axis and relatively low scores on the second axis. As all of the four items are related with fear or apprehension in the usage of computer-related devices, the first cluster was named "computer anxiety".

The second cluster includes four items: \#5 (I am worried if I can gather needed information.), \#9 (I am worried if I can accomplish the learning objective.), \#12 (I am worried about my achievements in online cooperative learning.), and \#13 (I feel apprehensive about learning via the Internet.) that had high category scores on the second correlation axis. All of the four items describe fear or apprehension in learning online. Therefore, the second cluster was labeled "online learning anxiety".

The third cluster also consists of four items: \#1 (I fear of communicating with a new acquaintance.), \#4 (I am tense and nervous while participating in group discussions.), \#6 (I am worried if I can communicate effectively with other learners.), and \#8 (I am worried if I can tell others what I want to say.) that had low category scores on both of the correlation axes. All of the four items are related with anxiety about communicating and cooperating with other learners, and therefore was given the name "communication anxiety".

Results of the pilot study suggest that participants' anxiety in online cooperative learning consists not only of technology -related anxiety but also anxiety about the learning process and achievements, and fear or apprehension to communicate and collaborate with others.

\section{MAIN STUDY}

Based on the results of the pilot study, a questionnaire survey was conducted from October 15th to 26th, 2013, with a purpose of developing and validating the OCLAS.

\section{A. Participants}

Participants were 56 university students: 29 Japanese 
first-year university students participating in Korean language classes, and 27 Korean third-year students taking Japanese classes. Participants had never communicated with each other and were to experience online cooperative learning activities in a group of five or six: two or three Japanese students and two or three Korean students.

\section{B. Questionnaire}

A questionnaire survey on the following 13 anxiety items that were decided as the initial OCLAS in the pilot study was administered to the participants. The questionnaire assesses participants' anxiety in online cooperative learning on a 4-point Likert scale ranging from 1 (strongly disagree) to 4 (strongly agree).

The initial version of OCLAS

1) I feel apprehensive about learning via the Internet.

2) I am worried if I can tell others what I want to say.

3) I am tense and nervous while participating in group discussions.

4) I feel apprehensive about using computers.

5) I am worried if I can accomplish the learning objective.

6) I fear of making mistakes I cannot correct.

7) I am worried about my achievements in online cooperative learning.

8) I am worried if I can communicate effectively with other learners.

9) I am worried if I can properly operate the system.

10) I am worried if I can understand computer-related terms.

11) I fear of hitting the wrong key or clicking the wrong hyperlink.

12) I fear of communicating with a new acquaintance.

13) I am worried if I can gather needed information.

\section{Procedure}

Participants first got lectured about the objectives and tasks of the online cooperative learning activities they were to experience. Then, participants were demonstrated and lectured how to operate the learning management system (LMS) they were to use for the cooperative activities. After the demonstration and lecture, participants answered to the questionnaire.

\section{RESUlts}

Among the 56 participants, 54 valid responses were collected which means that the response rate was 96.43 percent. Hereinafter, the results of the 54 answers will be introduced and used for data analysis.

\section{A. Participants' Profile}

Table III shows the breakdown of participants by gender, experience of communicating with a person from their target language country, possession of a personal computer, possession of a smartphone, frequency of Internet use, and device used to access the Internet.

Nearly 80 percent of the participants were females. The reason for the large proportion of females is that all of the participants were language learners majoring in foreign language studies. Most of the participants (77.78 percent) commented that they have never communicated with a
Korean or Japanese before. Participants' personal computer ownership (64.81 percent) is relatively high but is lower than the penetration rate of personal computers in Japan $(75.8$ percent as of March, 2013) [28] and Korea (82.3 percent as of FY 2012) [29], while smartphone ownership (92.59 percent) is much higher than the penetration rate of smartphones in Japan (49.5 percent as of March 2013) [28] and Korea (70.14 percent as of June, 2014) [30]. Most of the participants (74.08 percent) mentioned that they use the Internet every day, and most of them (74.07 percent) responded that they access the Internet via a smartphone.

TABLE III: PROFILE OF THE PARTICIPANTS

\begin{tabular}{|c|c|c|c|}
\hline \multicolumn{2}{|c|}{ Profile of participants } & \multirow{2}{*}{$\frac{\text { Frequency }}{12}$} & \multirow{2}{*}{$\frac{\%}{22.22 \%}$} \\
\hline \multirow{3}{*}{ Gender } & Male & & \\
\hline & Female & 42 & $77.78 \%$ \\
\hline & Total & 54 & $100.00 \%$ \\
\hline \multirow{3}{*}{$\begin{array}{l}\text { Experience of } \\
\text { communicating with a } \\
\text { Korean/Japanese }\end{array}$} & Yes & 16 & $22.22 \%$ \\
\hline & No & 38 & $77.78 \%$ \\
\hline & Total & 54 & $100.00 \%$ \\
\hline \multirow{3}{*}{$\begin{array}{l}\text { Possession of a personal } \\
\text { computer }\end{array}$} & Yes & 35 & $64.81 \%$ \\
\hline & No & 19 & $35.19 \%$ \\
\hline & Total & 54 & $100.00 \%$ \\
\hline \multirow{3}{*}{ Possession of a smartphone } & Yes & 50 & $92.59 \%$ \\
\hline & No & 4 & $7.41 \%$ \\
\hline & Total & 54 & $100.00 \%$ \\
\hline \multirow{5}{*}{ Frequency of Internet use } & Everyday & 40 & $74.08 \%$ \\
\hline & 3-4 times a week & 6 & $11.11 \%$ \\
\hline & 1-2 times a week & 7 & $12.96 \%$ \\
\hline & Seldom & 1 & $1.85 \%$ \\
\hline & Total & 54 & $100.00 \%$ \\
\hline \multirow{3}{*}{ Internet access } & $\mathrm{PC}$ & 14 & $25.93 \%$ \\
\hline & Smartphone & 40 & $74.07 \%$ \\
\hline & Total & 54 & $100.00 \%$ \\
\hline
\end{tabular}

\section{B. Descriptive Statistics}

Means and standard deviations for the entire sample, and correlation of the 13 items and the total scale are presented in Table IV. Results of the questionnaire survey reveal that participants had high levels $(M>3.00)$ of anxiety in item \#2 (I am worried if I can tell others what I want to say.). On the other hand, participants had relatively low level $(M<2.50)$ of anxiety in item \#4, (I feel apprehensive about using computers.), \#6 (I fear of making mistakes I cannot correct.), \#9 (I am worried if I can properly operate the system.), \#10 (I am worried if I can understand computer-related terms.), \#11 (I fear of hitting the wrong key or clicking the wrong hyperlink.), \#12 (I fear of communicating with a new acquaintance.), and \#13 (I am worried if I can gather needed information.).

Five out of seven items with low mean scores (item \#4, \#6, $\# 9, \# 10, \# 11)$ are related with anxiety in using computers and the Internet for online cooperative learning. Rationale for the comparatively low anxiety for using computers and the Internet is likely the relatively high possession rate of personal computers and smartphones, and the high frequency 
of participants' Internet usage.

The 13 items of the initial OCLAS had correlations ranging from .40 to .84 with the total score (I-T correlation). No items correlated less than .40 . Therefore, all of the 13 items were selected for further analysis. Reliability estimate for the initial OCLAS was .88 .

TABLE IV: DESCRIPTIVE STATISTICS FOR THE INITIAL OCLAS

\begin{tabular}{|c|c|c|c|}
\hline Items & M & SD & $r$ \\
\hline $\begin{array}{l}\text { I feel apprehensive about learning via } \\
\text { the Internet. }\end{array}$ & 2.59 & 0.86 & .57 \\
\hline $\begin{array}{l}\text { 2. I am worried if I can tell others what I } \\
\text { want to say. }\end{array}$ & 3.06 & 0.74 & .58 \\
\hline $\begin{array}{l}\text { I am tense and nervous while } \\
\text { participating in group discussions. }\end{array}$ & 2.89 & 0.60 & .40 \\
\hline $\begin{array}{l}\text { I feel apprehensive about using } \\
\text { computers. }\end{array}$ & 2.26 & 0.94 & .70 \\
\hline $\begin{array}{l}\text { I am worried if I can accomplish the } \\
\text { learning objective. }\end{array}$ & 2.74 & 0.71 & .56 \\
\hline $\begin{array}{l}\text { I fear of making mistakes I cannot } \\
\text { correct. }\end{array}$ & 2.39 & 0.86 & .73 \\
\hline $\begin{array}{l}\text { 7. I am worried about my achievements in } \\
\text { online cooperative learning. }\end{array}$ & 2.50 & 0.64 & .58 \\
\hline $\begin{array}{l}\text { I am worried if I can communicate } \\
\text { effectively with other learners. }\end{array}$ & 2.85 & 0.68 & .49 \\
\hline $\begin{array}{l}\text { 9. I am worried if I can properly operate the } \\
\text { system. }\end{array}$ & 2.33 & 0.97 & .82 \\
\hline $\begin{array}{l}\text { I am worried if I can understand } \\
\text { computer-related terms. }\end{array}$ & 2.33 & 0.85 & .63 \\
\hline $\begin{array}{l}\text { I fear of hitting the wrong key or } \\
\text { clicking the wrong hyperlink. }\end{array}$ & 2.48 & 0.82 & .84 \\
\hline $\begin{array}{l}\text { 12. I fear of communicating with a new } \\
\text { acquaintance. }\end{array}$ & 2.30 & 0.82 & .65 \\
\hline $\begin{array}{l}\text { 13. I am worried if I can gather needed } \\
\text { information. }\end{array}$ & 2.31 & 0.75 & .74 \\
\hline Total & 33.04 & 6.58 & 1.00 \\
\hline
\end{tabular}

\section{Exploratory Factor Analysis}

With the purpose of developing a multidimensional measure for online cooperative learning anxiety, exploratory factor analysis was conducted to select items to form sub-scales and to assess the construct validity of the instrument. After varimax rotation, a three-factor solution was chosen, according to the tendency of the decrease of the eigenvalue (first axis: 3.178 , second axis: 1.948, third axis: 1.928, fourth axis: 0.783 ), eigenvalue $>1$ criterion, and the proportion of variance (first axis: 24.45 percent, second axis: 14.98 percent, third axis: 14.81 percent, fourth axis: 6.02 percent) (see Table V). The three factors accounted for 54.24 percent of the cumulative variance.

The retained three factors correspond to the three clusters identified in the pilot study: computer anxiety, communication anxiety, and online learning anxiety. Therefore, it is suggested that anxiety in online cooperative learning is consisted of technology-related anxiety, learning anxiety and social anxiety.

The first factor consists of 5 items: item \#4 (I feel apprehensive about using computers.), \#6 (I fear of making mistakes I cannot correct.), \#9 (I am worried if I can properly operate the system.), \#10 (I am worried if I can understand computer-related terms.), and \#11 (I fear of hitting the wrong key or clicking the wrong hyperlink.) and accounted for 24.45 percent of the total variance (eigenvalue 3.178). The items within the factor had rotated factor loadings ranging from 0.569 to 0.848 . As all of the five items are related with fear or apprehension in using computer-related devices, the first cluster was labeled as "computer anxiety".

TABLE V: FACTOR LOADINGS FOR ANXIETY IN ONLINE COOPERATIVE LEARNING

\begin{tabular}{|c|c|c|c|}
\hline Items & Axis1 & Axis 2 & Axis 3 \\
\hline \multicolumn{4}{|l|}{ Factor I: Computer Anxiety } \\
\hline $\begin{array}{l}\text { I am worried if I can properly operate the } \\
\text { system. }\end{array}$ & 0.848 & 0.140 & 0.203 \\
\hline $\begin{array}{l}\text { I1. fear of hitting the wrong key or clicking } \\
\text { the wrong hyperlink. }\end{array}$ & 0.754 & 0.206 & 0.234 \\
\hline $\begin{array}{l}\text { I fear of making mistakes I cannot } \\
\text { correct. }\end{array}$ & 0.735 & 0.288 & 0.075 \\
\hline $\begin{array}{l}\text { I feel apprehensive about using } \\
\text { computers. }\end{array}$ & 0.723 & 0.059 & 0.231 \\
\hline $\begin{array}{l}\text { I am worried if I can understand } \\
\text { computer-related terms. }\end{array}$ & 0.569 & 0.008 & 0.117 \\
\hline
\end{tabular}

Factor II: Communication Anxiety

\begin{tabular}{l|c|c|c}
\hline $\begin{array}{l}\text { 8. I am worried if I can communicate } \\
\text { effectively with other learners. }\end{array}$ & 0.112 & 0.665 & 0.085 \\
\hline $\begin{array}{l}\text { I am tense and nervous while } \\
\text { participating in group discussions. }\end{array}$ & 0.003 & 0.647 & 0.152 \\
\hline $\begin{array}{l}\text { I am worried if I can tell others what I } \\
\text { want to say. }\end{array}$ & 0.264 & 0.633 & 0.067 \\
\hline $\begin{array}{l}\text { I fear of communicating with a new } \\
\text { acquaintance. }\end{array}$ & 0.150 & 0.580 & 0.459 \\
\hline
\end{tabular}

Factor III: Online Learning Anxiety

\begin{tabular}{l|c|c|c}
\hline $\begin{array}{l}\text { I am worried about my achievements in } \\
\text { online cooperative learning }\end{array}$ & 0.225 & 0.116 & 0.729 \\
\hline $\begin{array}{l}\text { I am worried if I can accomplish the } \\
\text { learning objective. }\end{array}$ & 0.103 & 0.188 & 0.709 \\
\hline $\begin{array}{l}\text { I feel apprehensive about learning via the } \\
\text { Internet. }\end{array}$ & 0.450 & 0.070 & 0.513 \\
\hline $\begin{array}{l}\text { I am worried if I can gather needed } \\
\text { information. }\end{array}$ & 0.367 & 0.384 & 0.462 \\
\hline \hline
\end{tabular}

The second factor includes four items: \#2 (I am worried if I can tell others what I want to say.), \#3 (I am tense and nervous while participating in group discussions.), \#8 (I am worried if I can communicate effectively with other learners.), and \#12 (I fear of communicating with a new acquaintance.), and explained 14.98 percent of the total variance (eigenvalue 1.948). Items had rotated factor loadings ranging from 0.580 to 0.665 . The four items are associated with anxiety in communicating and cooperating online with others, and therefore the second factor was termed "communication anxiety".

The third factor comprises four items: \#1 (I feel apprehensive about learning via the Internet.), \#5 (I am worried if I can accomplish the learning objective.), \#7 (I am worried about my achievements in online cooperative learning), and \#13 (I am worried if I can gather needed information.), which accounted for 14.81 percent of the variance (eigenvalue 1.925). The items in the third factor had rotated factor loadings between 0.462 and 0.729 . Since the items refer to fear or apprehension about the online learning process and achievements, the third factor was labeled "online learning anxiety". 


\section{Reliability Analysis}

Reliability analysis was performed to determine the internal consistency of the 13-item OCLAS. Internal consistency of the items was computed by using Cronbach's coefficient alpha. Reliability analysis produced results indicating comparatively high level $(.90>\alpha>.80)$ or acceptable level $(.80>\alpha>.70)$ of internal consistency for the three sub-scales (see Table VI). Internal reliability analysis revealed that deletion of any of the 13 items would not significantly increase the value of coefficient alpha of the sub-scales. Consequently, no items were deleted from the scale, and coefficient alpha for the total instrument indicated high internal consistency of the OCLAS $(\alpha=.88)$.

TABLE VI: INTERNAL CONSISTENCIES AND INTER-CORRELATIONS OF THE OVERALL SCALE AND THE SUB-SCALES

\begin{tabular}{ll|c|c|c|c|c}
\hline \hline \multicolumn{1}{c|}{ Factor } & CpA & OLA & CmA & Total & $\alpha$ \\
\hline \hline 1. Computer anxiety & - & $.58 * *$ & $.37 * *$ & $.88 * *$ & .88 \\
2. Online learning anxiety & & - & $.50 * *$ & $.82 * *$ & .75 \\
3. Communication anxiety & & & - & $.71 * *$ & .75 \\
\hline \multicolumn{4}{c|}{ Total } \\
\hline \hline
\end{tabular}

***p<.01

Inter-correlations between the sub-scales and the total scale were calculated using Pearson's correlation analysis (Table VI). Results of the correlation analysis show that inter-correlation between sub-scales were moderate $(r=.37$ to .58), and correlation between the sub-scales and the total scale were high ( $r=.71$ to .88 ). Results suggest that the three sub-scales are essential factors for the OCLAS, while they can be sufficiently distinguished from each other.

\section{E. Discriminant Validity Analysis}

TABLE VII: GOOD-POOR ANALYSIS OF OCLAS

\begin{tabular}{|c|c|}
\hline Items & $t$ \\
\hline \multicolumn{2}{|l|}{ Factor I: Computer Anxiety } \\
\hline 4. I feel apprehensive about using computers. & $6.05 * *$ \\
\hline 6. I fear of making mistakes I cannot correct. & $5.73 * *$ \\
\hline 9. I am worried if I can properly operate the system. & $9.20 * *$ \\
\hline 10. I am worried if I can understand computer-related terms. & $3.71 * *$ \\
\hline $\begin{array}{l}\text { I fear of hitting the wrong key or clicking the wrong } \\
\text { hyperlink. }\end{array}$ & $6.59 * *$ \\
\hline
\end{tabular}

Factor II: Communication Anxiety

\begin{tabular}{l|l}
\hline 2. I am worried if I can tell others what I want to say. & $3.37 * *$ \\
\hline $\begin{array}{l}\text { 3. I am tense and nervous while participating in group } \\
\text { discussions. }\end{array}$ & $2.23^{*}$ \\
\hline $\begin{array}{l}\text { I am worried if I can communicate effectively with other } \\
\text { learners. }\end{array}$ & $2.73^{*}$ \\
\hline 12. I fear of communicating with a new acquaintance. & $5.76^{* *}$ \\
\hline
\end{tabular}

Factor III: Online Learning Anxiety

\begin{tabular}{l|l}
\hline 1. I feel apprehensive about learning via the Internet. & $6.23 * *$ \\
\hline 5. I am worried if I can accomplish the learning objective. & $3.64 * *$ \\
\hline $\begin{array}{l}\text { 7. I am worried about my achievements in online } \\
\text { cooperative learning }\end{array}$ & $4.94 * *$ \\
\hline $\begin{array}{l}\text { 13. I am worried if I can gather needed information. } \\
* p<.05, * * p<.01\end{array}$ & $5.58 * *$ \\
\hline \hline
\end{tabular}

For assessment of discriminant validity of the OCLAS, good-poor analysis (GP analysis) was performed. Based on the total scores of the OCLAS, participants were divided into three groups: high-score group, middle-score group, and low-score group. Then, difference in the mean scores for the high-score group and low-score group was examined for every item to determine discrimination of each anxiety item (see Table VII). As a result, the high-score group had significantly higher mean scores for all items of the OCLAS compared to the low-score group $(p<.05)$.

\section{DISCUSSIONS}

The purpose of the present study was to identify the contents and structure of university students' anxiety in online cooperative learning, and consequently, develop and validate the OCLAS. The design of the study included two steps: the pilot study which purposed to identify online cooperative learning anxiety statements and create a set of candidate items of the OCLAS, and the main study which aimed to develop and validate the OCLAS.

Regarding the first research question "What are university students uneasy, fearful or worried about when they learn cooperatively with new acquaintances via the Internet?", results of the questionnaire surveys show that university students majoring in foreign studies are highly anxious about telling their feelings and ideas to others, participating in group discussion, and communicating effectively with others.

With regard to the second research question "How many factors assist to explain the structure of learners' anxiety for online cooperative learning?", exploratory factor analysis yielded three factors for online cooperative learning, namely, "computer anxiety", "communication anxiety", and "online learning anxiety".

Referring to the third research question "How valid and reliable is the OCLAS?", results of the factor analysis and correlation analysis suggest that the determined three sub-scales are essential factors for the OCLAS, and they can be sufficiently distinguished from each other. Additionally, good-poor analysis indicated that the 13 items of the OCLAS have high discriminant validity. Furthermore, reliability analysis showed high internal consistency of the OCLAS, and high or acceptable internal consistency of the three sub-scales. Results of the study show that OCLAS has the potential to be a useful tool to measure what aspects of online cooperative learning are perceived to be barriers by university students.

\section{CONCLUSION}

The development of the OCLAS addressed the need for a measure of anxiety in communicating and cooperating with other learners. Results of the present study indicate that university students' anxiety in online cooperative learning is not a technology-related unidimensional trait but is a threedimensional trait, consisting of "computer anxiety", "communication anxiety", and "online learning anxiety". Since the Internet is a powerful and global medium for communication as well as a medium for accessing information, and Internet-based cooperative learning requires interaction and communication among the learners, it is crucial to focus on learners' social anxiety to ensure and enhance the quality of online cooperative learning. 
As the participants of the current study were university students who major in foreign language studies and were mainly females, it is needed to conduct further, cumulative validation research in order to improve the OCLAS. At first, using another sample from other majors, ages, gender, nationality, experience in communicating with a person from the target language country, and experience and frequency in using computers or smartphones is recommended for future generalization of the OCLAS items. With the improvement of the OCLAS, further research should be stimulated and better knowledge about the learners' psychological mechanism of online cooperative learning could be shared, leading to promote online cooperative learning.

Given the findings of this study, it is necessary to explore relationships between learners' online cooperative learning anxiety and their attitude, behavior and achievements in Internet-based cooperative learning. Also, future studies should investigate the nature of relationships between online cooperative learning anxiety and other psychological, personal, and educational variables such as intrinsic motivation [6], [7], learning strategies [31], and learning belief [32], [33], that affect the learning process and achievement.

In addition, the findings of this study must contribute to suggest educators how to reduce learners' anxiety in online cooperative learning activities. That is to say, as with face-to-face cooperative learning, the role of the teacher acting as a facilitator is important to decrease learners' anxiety and to enhance promotive interaction in online cooperative learning. Actually, many previous studies suggest the significance of facilitators in online cooperative learning [34]-[39]. Therefore, it is expected to specify the roles and functions of online facilitators, with the purpose of helping learners reduce their anxiety in Internet-based cooperative learning, and learn effectively.

\section{ACKNOWLEDGEMENT}

This work was supported in by a grant from the Japan Society for Promotion of Science (JSPS) KAKENHI Grant Number 25350360.

\section{REFERENCES}

[1] T.-K. Neo, M. Neo, and J. W. J Kwok, "Engaging students in a multimedia cooperative learning environment: A Malaysian experience," in Proc. Ascilite Auckland, 2009, pp. 674-683.

[2] J.-W. Li, Y.-T. Wang, and Y.-C. Chang, "A learning-community recommendation approach for web-based cooperative learning," World Academy of Science, Engineering and Technology, vol. 5, pp. 614-618, 2013.

[3] T. Panitz. A definition of collaborative vs cooperative learning. [Online]. Available: http://www.londonmet.ac.uk/deliberations/collaborative-learning/pani tz-paper.cfm

[4] R. T. Johnson and D. W. Johnson, "An overview of cooperative learning," in Creativity and Collaborative Learning, J. Thousand, A Villa, and A. Nevin, Ed., Baltimore: P. H. Brookes Press, 1994, pp. 31-44.

[5] D. W. Johnson and R. T. Johnson, "Making cooperative learning work," Theory Into Practice, vol. 38, no. 2, pp. 67-73, 1999.

[6] W. Assinder, "Peer teaching, peer learning: One model," ELT Journal, vol. 45, pp. 218-229, 1991.

[7] M. Hanze and R. Berger, "Cooperative learning, motivational effects, and student characteristics: An Experimental study comparing cooperative learning and direct instruction in 12th grand physics classes," Learning and Instruction, vol. 17, pp. 29-41, 2007.

[8] R.-J. Chuang, M.-C. Chiang, C.-S. Yang, and C.-W. Tsai, "Social networks-based adaptive pairing strategy for cooperative learning," Educational Technology \& Society, vol. 15, no. 3, pp. 226-239, 2012

[9] C. A. Bliss and C. Lawrence, "From posts to patterns: A metric to characterize discussion board activity in online courses," Journal of Asynchronous Learning Networks, vol. 13, no. 2, pp. 15-32, 2009.

[10] C. A. Bliss and B. Lawrence, "Is the whole greater than the sum of its parts? A comparison of small group and whole class discussion board activity in online courses," Journal of Asynchronous Learning Networks, vol. 13, no. 4, pp. 25-39, 2009.

[11] R. Hauser, R. Paul, and J. Bradley, "Computer self-efficacy, anxiety, and learning in online versus face to face medium," Journal of Information Technology Education: Research, vol. 11, pp. 141-154, 2012.

[12] M. R. Simonson, A. Matt, and M. M. Maurer, "Development of a standardized test of computer literacy and a computer anxiety index," Journal of Educational Computing Research, vol. 3, no. 2, pp. 231-247, 1987.

[13] R. G. Saadé and D. Kira, "Computer anxiety in e-learning: the effect of computer self-efficacy," Journal of Information Technology Education, vol. 8, pp. 177-191, 2009.

[14] A. R. Alenezi, A. M. Abdul Karim, and A. Veloo, "An empirical investigation into the role of enjoyment, computer anxiety, computer self-efficacy and internet experience in influencing the students' intention to use e-learning: A case study from Saudi Arabian governmental universities," The Turkish Online Journal of Educational Technology, vol. 9, no. 4, 2010.

[15] H. K. Sam, A. E. A. Othman, and Z. S. Nordin, "Computer self-efficacy, computer anxiety, and attitudes toward the internet: A study among undergraduates in unimas," Educational Technology \& Society, vol. 8, no. 4, pp. 205-219, 2005.

[16] N. Mohamed and N. S. Abdul Karim, "Open source e-learning anxiety, self-efficacy and acceptance — A partial least square approach," International Journal of Mathematics and Computers in Simulation, vol. 6, no. 4, pp. 361-368, 2012.

[17] R. K. Heinssen, C. R. Glass, and L. A. Knight, "Assessing computer anxiety: Development and validation of the computer anxiety rating scale," Computers in Human Behavior, vol. 3, pp. 49-59, 1987.

[18] D. Havelka and F. Beasley, "An examination of the factor structure of the computer anxiety rating scale," Journal of College Teaching \& Learning, vol. 1, no. 4, pp. 51-56, 2004.

[19] J. B. Thatcher, M. L. Loughry, J. Lim, and D. H. McKnight, "Internet Anxiety: An empirical study of the effects of personality, beliefs, and social support," Information \& Management, vol. 44, pp. 353-363, 2007.

[20] C. Presno, "Taking the byte out of Internet anxiety: Instructional techniques that reduce computer/Internet anxiety in the classroom," Journal of Educational Computing Research, vol. 18, no. 2, pp. 147-161, 1998.

[21] M. J. Tsai, "The model of strategic e-learning: Understanding and evaluating student e-learning from metacognitive perspectives," Educational Technology \& Society, vol. 12, no. 1, pp. 34-48, 2009.

[22] S. A. Brown, R. M. Fuller, and C. Vician, "Who's afraid of the virtual world? Anxiety and computer-mediated communication," Journal of the Association for Information Systems, vol. 5, no. 2, pp. 79-107, 2004.

[23] Y. Nishimura, "An examination of state communication anxiety: Communication medium, and trait social anxiety," The Japanese Journal of Personality, vol. 13, no. 2, pp. 183-196, 2005.

[24] H. M. Satar and N. Ozdener, "The effects of synchronous CMC on speaking proficiency and anxiety: Text versus voice chat," The Modern Language Journal, vol. 92, no. 4, pp. 595-613, 2008.

[25] L. Rice and P. M. Markey, "The role of extraversion and neuroticism in influencing anxiety following computer-mediated interactions," Personality and Individual Differences, vol. 46, pp. 35-39, 2009.

[26] H. Yoshida, S. Tani, T. Uchida, J. Masui, and A. Nakayama, "Structural analysis of anxiety in online cooperative learning," International Journal of e-Education, e-Business, e-Management and e-Learning, vol. 3, no. 5, pp. 381-385, 2013.

[27] J. C. McCroskey, M. J. Beatty, P. Kearney, and T. G. Plax, "The content validity of the PRCA-24 as a measure of communication apprehension across communication contents," Communication Quarterly, vol. 33, no. 3, pp. 165-173, 1985.

[28] Communications Usage Trend Survey, Ministry of Internal Affairs and Communications, Tokyo, 2013. 
[29] H. Lim, "Innovative smart classes in Korea: Outcomes and concerns," presented at Mobilearn Asia 2013.

[30] M.-J. Lee. (2014). Korea's smartphone population tops milestone. [Online].

Available: http://blogs.wsj.com/korearealtime/2014/07/28/koreas-smartphone-po pulation-tops-milestone/

[31] J. N. Cabansag, "The attitudinal propensity of students toward strategies in English language learning," Researchers World, vol. 4, issue 2, 2013.

[32] E. S. N. Kaunang, "The effect of cooperative learning model and belief about science on the biology learning achievement by controlling the initial ability of students (Experiment study on eighth grade students of public junior high school in minahasa regency)," Journal of Education and Practice, vol. 5, no. 7, pp. 45-52, 2014.

[33] R. Fahiminia, S. Jahandar, and M. Khodabandehlou, "The impact of collaborative learning on iranian EFL learners' beliefs about vocabulary learning," Indian Journal of Fundamental and Applied Life Sciences, vol. 3, no. 2, pp. 150-163, 2013.

[34] M. Coghlan, "E-moderation - managing a new language?" presented at Net Working 2001 Conference.

[35] G. Kemshal-Bell. The on-line teacher, final report prepared for the project steering committee of the VET teacher and on-line learning project. ITAM. ESD. TAFENSW. [Online]. Available: http://cyberteacher.onestop.net/final per cent20report.pdf, 2001.

[36] M. McVay-Lynch, The On-Line Educator - A Guide to Creating the Virtual Classroom, London: Routledge, 2002.

[37] (2003). Australian flexible learning network (AFLN) effective on-line facilitation. Australian Flexible Learning Quick Guide Series. [Online]. Available: http://flexiblelearning.net.au.

[38] G. Packham, P. Jones, C. Miller, and B. Thomas, "Perceptions of effective e-moderation: A tutors viewpoint," presented at the Networked Learning Conference 2004, 2004.

[39] G. Packham, P. Jones, B. Thomas, and C. Miller, "Student and tutor perspectives of on-line moderation," Education + Training, vol. 48, no. 4, pp. 241-251, 2006.

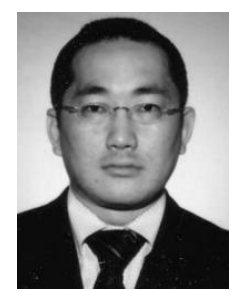

H. Yoshida was born in Nara, Japan in 1973. He received the MEd in educational technology from International Christian University, Japan in 2001. He is currently a professor at Tokoha University in Shizuoka, Japan. His research interests include online learning, cooperative learning, hypermedia education, and teacher education. 